universities, state-controlled departments, trade research institutes, etc. ; even the patent literature reveals little of what is going on in works and commercial laboratories. . . . It may be expected that the move towards centralised research on fundamental problems will continue in all countries, and that the rate of progress in any country will be closely related to the extent to which its research institutes are supported".

A. A. EldididaE.

\title{
TECHNOLOGY OF SOUND TRANSMISSION
}

Sound Transmission in Buildings

Practical Notes for Architects and Builders. By R. Fitzmaurice and William Allen. (Department of Scientific and Industrial Research.) Pp. viii50. (London : H.M. Stationery Office, 1939.) 4s. net.

$\mathrm{O}^{\mathrm{N}}$ E might justly express surprise that a report under this title should deal with an acute social problem of this critical stage in our civilization. "The gramophone and the loud-speaker are undoubtedly the greatest source of difficulty in a modern building. Not only have they become almost universal but year by year they become capable of greater undistorted acoustic output and the tendency is for them to be worked at a higher level of sound intensity on account of the greater realism which can thereby be obtained," say the authors of this report. Their main concern is to show how the fundamental principles which have been found to underlie modern types of soundinsulated structure must be put into building practice if good-neighbourliness is to survive in the life of the modern city.

The work on which this was based was carried out at the National Physical Laboratory and the Building Research Station. It began with simple cases of sound transmission through walls and floors, but investigations on the elements of a building structure taken separately proved insufficient ; interaction between walls, floors, etc., proved of the first importance. Units were built up on steel frames at the Building Research Station for this purpose and tests were also made of actual buildings. The conclusion reached is that so long as rigidly connected structures are used, no overall insulation to air-borne sounds can be expected to improve on that afforded by a 9 -in. brick wall.

Suggested practical constructions are given in this book to show how noise-insulation technique stands to-day. The subject is dealt with under three headings. The first section deals with the modes of transmission of air-borne and impact sounds, in which it is pointed out that though mass and rigidity of structure may stop the former, nothing but definite discontinuities can isolate the latter. In the second section figures are given in the form of simple nomograms to show the type of homogeneous construction which should be employed with a given external disturbance to give sufficient quietude for carrying out certain classes of occupation inside the building. These data are cleverly presented to avoid the usual tabulation of decibels or phons which might embarrass the architect unused to such technical terms. Three such figures are given: (1) for external air-borne noise ; (2) for indoor air-borne noise ; (3) for impact noise. The third section will possess the greatest interest to the practising architect and builder, for in it are given illustrative specifications in the application of discontinuous construction to flats, semi-detached houses, hospitals and offices. Experience gained in the construction of suspended ceilings and floating floors is placed at the disposal of those who will in the future be called upon to make use of it. No detail is too small to be overlooked; fireplaces, chimney-stacks and the plumbing fixtures are all designed specially to suit the construction, since these must be independent of the floating boxes of which the rooms virtually consist, and must be isolated from them in the outer shell of the building.

The authors claim that, armed with the information they give, it is possible to visualize a solution for almost any problem in noise insulation which may arise in connexion with building in the future. For example, it may be possible to do away with structural floors as separate elements and to use only floors and ceilings not rigidly connected to the shell. Buildings could then be constructed on a unit system, each story being separated from the next by a resilient pad. Although formerly it was thought that tie-rods were the weakest part, from the sound-transmission point of view, of a discontinuous structure, it has recently been found that wall ties of certain types used in cavity wall construction are quite effective insulators. These and other possible simplifications in structure will be tested at the Building Research Station.

The authors and publishers are to be congratulated on this book. There is bound to be a large amount of reconstruction-in the literal sense-after the War, and it is to be hoped that it may result in the application generally of the ideas here presented. 